\title{
New Insights into Muscle Fibre Types in Casertana Pig
}

\author{
Salvatore Velotto, Claudia Vitale, Tommaso Stasi, Antonio Crasto \\ Department of Soil, Plant, Environmental and Animal Production Sciences, Faculty of Agriculture Via \\ Università, University of Study of Naples Federico II, Portici, Italy
}

Received June 16, 2009

Accepted October 21, 2009

\begin{abstract}
Little is known about the Casertana pig. The aim of this study was to evaluate the effect of sex on histochemical and morphometrical characteristics of muscle fibres (myocytes) in this pure breed and to verify the presence of giant fibres as well as vascularity of the muscle. Finally, maximum shortening velocity and isometric tension were measured in single muscle fibres.

Sixteen Casertana pigs ( 8 males, 8 females) from a farm in Campania (Italy) were slaughtered at one year of age. Muscle tissues were obtained from psoas minor, rhomboideus and longissimus dorsi. Myofibres were stained for myosin adenosine triphosphatase, succinic dehydrogenase, and $\alpha$-amylase-periodic acid schiff. For all fibre types, the area and perimeter were measured. Slowtwitch oxidative fibres, fast-twitch glycolytic fibres and fast-twitch oxidative-glycolytic fibres were histochemically differentiated; an image-analyzing system was used. The results showed significant differences between the sexes in the size of all three fibre types. The psoas minor muscle had a high percentage of slow-twitch oxidative fibres and contained more capillaries per fibre and per $\mathrm{mm}^{2}$ than rhomboideus and longissimus dorsi, in which fast-twitch glycolytic fibres dominated. The cross-sectional area of all fibre types was larger in longissimus dorsi than in rhomboideus and psoas minor muscles; the giant fibres were present in the longissimus dorsi muscle only. Besides, isometric tension values were higher in fast-twitch glycolytic fibres than in the other ones. Variations in fibre type composition may contribute to meat quality.
\end{abstract}

Giant fibres, myosin adenosine triphosphatase, succinic dehydrogenase, capillaries, shortening velocity, isometric tension

The Casertana breed is an autochthonous pig breed of ancient origin, now threatened with extinction. In the past it was considered a very fine breed, raised in the Campania region and the surrounding area in South Italy. It was valued for its productive performance particularly regarding the fattening tendency. It is characterized by slow growth and massive accumulation of backfat; its coat is bright black and hairless. The purpose of this study was to complete the knowledge regarding the Casertana pig in order to valorise this breed and to study its meat quality characteristics. Porcine meat quality can be affected by variation in muscle fibre type composition (Depreux 2000). Muscle fibre types may be classified based on enzymatic activity; in this study the following nomenclature was used for myofibre types: FG (fast-contracting with glycolytic metabolism), FOG (fast contracting with glycolytic-oxidative metabolism) and SO (slow-contracting with oxidative metabolism). The aim of this study was to evaluate the effect of sex on the histochemical and morphometric characteristics of muscle fibres on the basis of myosin adenosine triphosphatase (myosin ATPase), succinic dehydrogenase (SDH), to analyse the contractile properties of pig muscle fibres and to determine the presence of giant fibres in the muscles considered. A high proportion of pigs $(85 \%)$ contain giant fibres in their muscles but these giant fibres usually represent less than $1 \%$ of the total myofibre population. Giant fibres possess enhanced adenosine triphosphatase activity and a high capacity for oxidative metabolism (indicated by succinate dehydrogenase activity) which is reflected ultrastructurally by the greatly heightened electron density of myofibrils and by an abnormally high percentage of mitochondria and lipid droplets (Handel et al. 1986). To visualize the blood capillaries the $\alpha$-amylase-periodic acid schiff ( $\alpha$-amylase-PAS)

Address for correspondence:

Dr. Salvatore Velotto, Phd.

Department of Soil, Plant, Environmental and Animal Production Sciences

Faculty of Agriculture, University of Study of Naples Federico II

Via Università, 133-80055 Portici (NA), Italy

Phone: $+390812539269-264$

Fax: +390817762886

E-mail: velotto@unina.it

http://www.vfu.cz/acta-vet/actavet.htm 
method was used; such reaction stains the basal membrane of the capillaries. The fibre type composition of different skeletal muscles could be one of the most important factors influencing the biochemical events associated with their conversion to meat (Wojtysiak et al. 2007). Recent evidence implies that fibre type proportions play a role in meat quality; in pigs it has been suggested that slow oxidative fibres contribute to both juiciness and tenderness (Fonseca et al. 2003).

\section{Materials and Methods}

The sampling of pig muscles

Muscle samples were collected from pigs of the pure Casertana breed killed in a slaughter house. Sixteen clinically healthy swine ( 8 males and 8 females) from a farm located in Benevento (Campania) were slaughtered at 1 year of age at a body mass of $150 \pm 10 \mathrm{~kg}$. Animals were reared in an extensive system and raised using the most traditional farming methods, the diet of swine shifted gradually from woodland forage and scraps to corn. The slaughter house had EEC mark with reference to rules 852/853/854/2004; 2076/2005; 1069/2009. Animals were treated according to the guidelines of the European Community on the treatment of experimental animals (Reg. CE 1/2005; directives 74/577/EEC; Law 4392 August 1978).

\section{Single fibre mechanics}

Single fibres were dissected under a stereomicroscope $(\times 10-60$ magnification $)$. At the end of dissection, fibres were bathed for $1 \mathrm{~h}$ in a skinning solution containing $1 \%$ Triton X-100 to ensure complete membrane solubility. Segments of 1-2 mm length were then cut from the fibres and light aluminium clips were applied at both ends. Skinning, relaxing, preactivating and activating solutions employed for mechanical experiments with single fibres were prepared as previously described (Pellegrino et al. 2003). Protease inhibitors (E64 $10 \mu \mathrm{mol} \cdot \mathrm{l}^{-1}$ and leupeptin $40 \mu \mathrm{mol} \cdot \mathrm{l}^{-1}$ ) were added to all solutions. Once the clips were applied, the fibre segment was mounted in the experimental set-up in a drop of relaxing solution between the force transducer (AME-801 SensorOne, Sausalito, California) and the electromagnetic puller (SI, Heideberg, Germany) equipped with a displacement transducer. Diameters and sarcomere length were measured at $\times$ 320 magnification. The contractile properties of each fibre were determined by measuring isometric tension $(\mathrm{P})$ during maximal activation $(\mathrm{pCa}=4.6)$, unloaded shortening velocity $\left(\mathrm{V}_{\mathrm{o}}\right)$ and series compliance $(\mathrm{SE})$ according to the slack test procedure (Edman 1979). All experiments were performed at $12^{\circ} \mathrm{C}$. Fibre typing was based on the use of myosin heavy chain (MHC) isoforms as molecular markers.

\section{Muscle histochemistry}

The following muscles were used in the study: m. psoas minor (Pm), m. longissimus dorsi (Ld) and $\mathrm{m}$. rhomboideus $(\mathrm{Rb})$. Samples from each muscle were collected and immediately frozen in liquid nitrogen $\left(-196{ }^{\circ} \mathrm{C}\right)$ and stored at $-80{ }^{\circ} \mathrm{C}$ until histochemical analyses were conducted. Transverse serial sections $(8 \mu \mathrm{m})$ were cut in a cryostat (LEICA CM 1100) at $-20^{\circ} \mathrm{C}$ and transferred to glass cover slips.

\section{Myosin ATPase and succinic dehydrogenase (combined histochemical staining)}

The sections were stained histochemically for myosin ATPase (myosin ATPase reveals muscular contraction) and succinic dehydrogenase (SDH reveals metabolism) simultaneously on the same myofibres (Solomon and Dunn 1988; Velotto et al. 2004). The method used for combined histochemical staining (acid myosin ATPase + $\mathrm{SDH}$ ) consisted of several steps. Acid pre-incubation was performed at room temperature for 20 min, followed by two 1-min rinses of $\mathrm{CaCl}_{2}$ in tris-hydroxymethyl-aminomethane buffer. Nitro-blue-tetrazolium (NBT) incubation was performed for $\mathrm{SDH}^{2}$ activity at $37^{\circ} \mathrm{C}$ for $20 \mathrm{~min}$, followed by two rinses in distilled water. Myofibrillar acid ATPase was performed at $37^{\circ} \mathrm{C}$ at $\mathrm{pH} 9.45$ for $50 \mathrm{~min}$, followed by three 30 -s rinses in $\mathrm{CaCl}_{2}$ solution and incubation in $\mathrm{CoCl}_{2}$ for $3 \mathrm{~min}$. A standard ammonium sulphide staining of the acid ATPase procedure was performed and cover slips were applied using glycerol jelly.

The basic myosin ATPase method was used for the first control procedure, consisting of sodium-cacodylate and sucrose incubation for $5 \mathrm{~min}$, followed by two 1-min rinses in $\mathrm{CaCl}_{2}$ in tris-hydroxymethyl-aminomethane buffer rinse solution. Sigma 221 and $\mathrm{CaCl}_{2}$ solutions were used for $15 \mathrm{~min}, \mathrm{pH}$ 10.3-10.5, followed by two 1-min rinses in $\mathrm{CaCl}_{2}$ and tris hydroxymethyl aminomethane buffer (Merck \& Co. USA). For acid ATPase the procedure was performed at $37^{\circ} \mathrm{C}$ at a $\mathrm{pH} 9.4$ for 50 min with three 30 -s rinses in $\mathrm{CaCl}_{2}$ solution and incubation for $3 \mathrm{~min}$ in $\mathrm{CoCl}_{2}$, followed by ammonium sulphide staining. Cover slips were applied using glycerol jelly.

The SDH method was used for the second control procedure, consisting of different phases: incubation in NBT at $37{ }^{\circ} \mathrm{C}$ for $20 \mathrm{~min}$, followed by two rinses in distilled water and formaldehyde immersion for $10 \mathrm{~min}$. Cover slips were applied using glycerol jelly.

$\alpha$-amylase-PAS (periodic acid-Schiff reaction)

To visualize blood capillaries the $\alpha$-amylase-PAS (periodic acid-Schiff reaction) method was utilized, staining their basal lamina, as employed successfully in horses, calves, and pigs (Henckel et al. 1998). The average number of capillaries adjacent to all fibre types (number of capillaries/number of counted muscle fibres) and the average number of capillaries per $\mathrm{mm}^{2}$ (number of capillaries/analyzed muscle area) were counted in psoas minor, longissimus dorsi and rhomboideus muscles. 
Fibre size

Fibre size was determined from the sections used to determine the number of myofibres. The area, perimeter and maximum and minimum diameter were measured using the image-analysing system LAS (Leica Application Suite Interactive measurement). For each muscle not less than 200 fibres measured from eight random fields were determined. The average fibre size was calculated.

Statistical analysis

Data were processed by analysing the variances, and means were determined by following the general linear model (Proc GLM; SAS, 1992) in which the factors considered are fixed and the effect of the other factors is expressed as deviation from the general average $(\mu)$. The model used was:

$y i j k l=\mu+\operatorname{Sexi}+\mathrm{Muj}+\mathrm{Ftk}+(\mathrm{sex} * \mathrm{Ft}) \mathrm{ik}+(\mathrm{Mu} * \mathrm{Ft}) j \mathrm{k}+$ eijkl;

yijklm $=$ value of lth relative observation to the kth fibre type of the jth muscle; of ith sex.

Sexi $=$ fixed effect of the ith $\operatorname{sex}(i=1,2)$.

Muj = fixed effect of the jth muscle $(\mathrm{j}=1,2,3)$.

$\mathrm{Ftk}=$ fixed effect of the kth fibre type $(\mathrm{k}=1,2,3)$.

$(\mathrm{Sex} * \mathrm{Ft}) \mathrm{ik}=$ fixed effect of the ith sex with the kth fibre type.

$(\mathrm{Mu} * \mathrm{Ft}) \mathrm{jk}=$ fixed effect of the jth muscle with the kth fibre type.

eijkl $=$ residual error.

The significance between the mean values was evaluated using Student's $t$-test.

\section{Results}

Histochemistry results revealed three fibre types: FG, with high myosin ATPase activity and low oxidative activity; FOG, with moderate myosin ATPase activity and intermediate oxidative activity; and SO, with low myosin ATPase and high oxidative activity.

The Pm muscle (Plate I and II, Figs 1 and 3) is the darkest muscle showing the highest percentage of SO fibres, followed by the Rb muscle (Plate III, Figs 5 and 6). The Ld muscle (Plate I and II, Figs 2 and 4 ) is the lightest muscle, showing the highest percentage of FG fibres.

$\mathrm{Pm}$ and $\mathrm{Rb}$ muscles show similar percentages of muscle fibre types, the SO is the highest (48 vs. 43 ), followed by the FOG (35 vs. 35 ), and the FG fibres (17 vs. 22 ). In the Ld muscle the FG is the highest (46\%), followed by the FOG (30\%), and the SO fibres $(24 \%)$.

The examined muscles showed a unique distribution of fibres composed of clusters of SO fibres that were surrounded by FOG and FG fibres (Plate IV, Fig. 7). The results of the analysis of variance showed significant muscle $\times$ fibre and sex $\times$ fibre interaction $(P<0.001)$ for the morphometric characteristics evaluated. In particular, the dimensions of $\mathrm{FG}$, FOG and SO fibres in the Ld muscle were higher than in $\mathrm{Rb}$ and Pm muscles (Table 1).

The differences between $\mathrm{Ld}$ and $\mathrm{Rb}$, with regard to the fibre area were $24 \%$ for FG (5001.84 vs.3785.77, $P<0.001), 12 \%$ for FOG (3445.46 vs.3021.19, $P<0.001$ ) and $22 \%$ for SO (5529.16 vs.4323.14, $P<0.001)$. The differences between $\mathrm{Ld}$ and Pm, with

Table 1. Mean value and variation coefficient (v.c.,\%) of morphometric characteristics of fibre types in the considered muscles

\begin{tabular}{|c|c|c|c|c|c|c|}
\hline \multirow{3}{*}{ Muscle* } & \multicolumn{6}{|c|}{ Fibre Types } \\
\hline & \multicolumn{2}{|c|}{ FG } & \multicolumn{2}{|c|}{ FOG } & \multicolumn{2}{|c|}{ SO } \\
\hline & mean & v.c., $\%$ & mean & v.c., $\%$ & mean & v.c. $\%$ \\
\hline \multicolumn{7}{|c|}{ Area $/ \mathrm{mm}^{2}$} \\
\hline $\mathrm{Pm}$ & $2562.61^{\mathrm{A}}$ & 27 & $1766.42^{\mathrm{A}}$ & 25 & $2468.83^{\mathrm{A}}$ & 27 \\
\hline $\mathrm{Rb}$ & $3785.77^{\mathrm{B}}$ & 20 & $3021.19^{\mathrm{B}}$ & 20 & $4323.14^{\mathrm{B}}$ & 24 \\
\hline Ld & $5001.84^{\mathrm{C}}$ & 30 & $3445.46^{\mathrm{C}}$ & 28 & $5529.16^{\mathrm{C}}$ & 26 \\
\hline \multicolumn{7}{|c|}{ Perimeter/mm } \\
\hline $\mathrm{Pm}$ & $218.45^{\mathrm{A}}$ & 12 & $194.36^{\mathrm{A}}$ & 11 & $211.14^{\mathrm{A}}$ & 10 \\
\hline $\mathrm{Rb}$ & $264.10^{\mathrm{B}}$ & 10 & $241.87^{\mathrm{B}}$ & 14 & $279.93^{\mathrm{B}}$ & 13 \\
\hline $\mathrm{Ld}$ & $313.90^{\mathrm{C}}$ & 12 & $267.17^{\mathrm{C}}$ & 12 & $309.90^{\mathrm{C}}$ & 14 \\
\hline
\end{tabular}

Different letters in the column indicate significant level of $P<0.001$ (A vs. B vs. C)

$* \mathrm{Pm}=\mathrm{m}$. psoas minor $\mathrm{Rb}=\mathrm{m}$. rhomboideus; $\mathrm{Ld}=\mathrm{m}$. longissimus dorsi 
Table 2. Mean value and variation coefficient (v.c.,\%) of morphometric characteristics of fibre types in relation to sex

\begin{tabular}{|c|c|c|c|c|c|c|}
\hline \multirow{3}{*}{ Sex } & \multicolumn{6}{|c|}{ Fibre Types } \\
\hline & \multicolumn{2}{|c|}{ FG } & \multicolumn{2}{|c|}{ FOG } & \multicolumn{2}{|c|}{ SO } \\
\hline & mean & v.c., $\%$ & mean & v.c., $\%$ & mean & v.c., $\%$ \\
\hline \multicolumn{7}{|c|}{ Area $/ \mathrm{mm}^{2}$} \\
\hline Males & $4077.18^{\mathrm{a}}$ & 30 & $3259.05^{\mathrm{A}}$ & 26 & $4690.38^{A}$ & 27 \\
\hline Females & $3445.38^{b}$ & 31 & $2225.74^{\mathrm{B}}$ & 31 & $3463.24^{\mathrm{B}}$ & 28 \\
\hline \multicolumn{7}{|c|}{ Perimeter/mm } \\
\hline Males & $268.2^{\mathrm{a}}$ & 10 & $235.02^{\mathrm{A}}$ & 8 & $272.79^{\mathrm{A}}$ & 8 \\
\hline Females & 218.25 & 7 & $172.83^{\mathrm{B}}$ & 7 & $205.98^{\mathrm{B}}$ & 8 \\
\hline
\end{tabular}

Different letters in the column indicate significant level of $P<0.05$ (a vs. b) and $P<0.001$ (A vs. B)

Table 3. Mean value and variation coefficient (v.c.,\%) of isometric tension and maximum shortening velocity

\begin{tabular}{|c|c|c|c|c|c|}
\hline \multicolumn{6}{|c|}{ Fibre Types } \\
\hline \multicolumn{2}{|c|}{ FG } & \multicolumn{2}{|c|}{ FOG } & \multicolumn{2}{|c|}{$\mathrm{SO}$} \\
\hline mean & v.c., $\%$ & mean & v.c., $\%$ & mean & v.c., $\%$ \\
\hline \multicolumn{6}{|c|}{ Isometric tension $/ \mathrm{mM} \cdot \mathrm{mm}^{-2}$} \\
\hline 36.25 & 22 & 82.42 & 11 & 27.61 & 13 \\
\hline \multicolumn{6}{|c|}{ Maximum shortening velocity/fibre length $\cdot \mathrm{s}^{-1}$} \\
\hline 4.46 & 8 & 2.04 & 9 & 0.18 & 6 \\
\hline
\end{tabular}

regard to the fibre area were $49 \%$ for FG (5001.84 vs.2562.61, $P<0.001), 49 \%$ for FOG (3445.46 vs.1766.42, $P<0.001)$ and $55 \%$ for SO (5529.16 vs.2468.83, $P<0.001)$. Significant differences between sexes for size of three fibre types (SO, FOG, FG) were noticed; in particular, in contrast to the study of Larzul et al. (1997) our study showed that the dimensions of FOG, FG and SO fibres in males are higher than in females (Table 2 ). The differences between males and females with regard to the fibre area were $15 \%$ for FG (4077.18 vs. $3445.38, P<0.05), 32 \%$ for FOG (3259.05 vs. $2225.74, P<0.001)$ and $26 \%$ for SO (4690.38 vs. $3463.24, P<0.001)$. Psoas minor muscle contained on average $439 \pm 56.04$ capillaries per $\mathrm{mm}^{2}$ and $1.5 \pm 0.2$ capillaries per fibre; rhomboideus muscle contained on average $331 \pm 33.71$ capillaries per $\mathrm{mm}^{2}$ and $1.5 \pm 0.1$ capillaries per fibre and longissimus dorsi muscle contained on average $201.13 \pm 25.06$ capillaries per $\mathrm{mm}^{2}$ and $0.9 \pm 0.2$ capillaries per fibre. A total of 160 single fibres, dissected from the three muscles considered, were analysed in a mechanical experiment. The slack sarcomere length was not significantly different among the fibre types: slow fibres $2.50 \pm 0.03 \mu \mathrm{m}$, fast twitch oxidative glycolytic fibres $2.58 \pm 0.05 \mu \mathrm{m}$, fast twitch glycolytic fibres $2.67 \pm 0.06 \mu \mathrm{m}$. The fibres were stretched by approximately $25 \%$ at rest and activation was induced at sarcomere lengths between $3.18 \pm 0.09 \mu \mathrm{m}$ for fast twitch glycolytic fibres. Determination of the isometric tension $\left(\mathrm{P}_{\mathrm{o}}\right)$ and of the unloaded shortening velocity $\left(\mathrm{V}_{\mathrm{o}}\right)$ revealed large diversity among the fibres. Slow fibres developed significantly less tension than fast fibres, with the exception of the fast twitch glycolytic fibres which also developed low isometric tension. In particular, $V_{\mathrm{o}}$ values increased from slow to fast twitch oxidative glycolytic fibres and fast twitch glycolytic fibres (Table 3 ).

\section{Discussion}

Skeletal muscle is composed of fibres classified according to their different contractile and metabolic properties. Myofibers were classified into three main groups, with the following nomenclature and characteristics: SO (slow twitch oxidative): small diameter, low level of glycolytic enzymes, moderate to high degree of aerobic ability; FOG (fast twitch oxidative 
glycolytic): intermediate diameter, moderate to high aerobic activity, together with a high concentration of cytochrome and oxidative enzymes; FG (fast twitch glycolytic): larger diameter, high level of glycogen, low levels of both cytochrome concentration and oxidative activity (Macedo et al. 2000). The SO or type I fibres containing high levels of myoglobin and oxygen storing proteins have a red appearance. Red muscle fibres tend to have more mitochondria and blood vessels than the white ones. They have slow contraction velocity and adaptation to endurance activities. The fast twitch glycolytic or IIB fibres have a white appearance; in these fibres myosin can split ATP very quickly. They show fast contraction and low resistance to fatigue. Finally the fast-twitch oxidative-glycolytic or IIA fibres have a red appearance, high contraction velocity and high resistance to fatigue. Several studies have demonstrated that myofibre typing is thought to contribute to meat quality. Besides, the pig has received increasing attention in recent years as a large domestic animal. From the most traditional point of view, pork meat is an important component of human food and several studies have examined the relationship between meat quality and muscle characteristics in various breeds (Davoli et al. 2003).

In the pig, there are light and dark muscles. Dark muscles contain predominantly type I and type IIA muscle fibres, while light muscles are primarily type IIB. Longissimus dorsi, gluteus medius, rectus femoris, biceps femoris, quadriceps femoris, vastus lateralis, and semimembranosus are light muscles. Masseter, trapezius, vastus intermedius, and triceps brachii are dark muscles. Some muscles, such as the semitendinosus, are divided into light and dark parts (Handel and Stickland 1986). We noticed that most muscles of the pig show a highly organized distribution pattern of fibre types mostly consisting of islets of slow type I fibres surrounded by an internal ring of fast type IIA and an external ring of fast type IIB fibres, in agreement with other authors (Lefaucheur et al. 1995). Muscle fibres are issued from myogenic precursor cells called myoblasts which proliferate, then fuse to form myotubes, and finally differentiate into muscle fibres (Picard et al. 2002).

In pigs, as in most mammals, ontogenesis of myofibres is a biphasic phenomenon that consists of the formation of a primary generation of muscle fibres between 35 and $55 \mathrm{~d}$ of gestation (dg), followed by a second generation between 55 and $90 \mathrm{dg}$ (Lefaucheur et al. 2003). The functional properties of a mammalian muscle are dictated in large part by its fibre composition. Most mammalian muscles contain a heterogeneous mixture of fibre types, whose relative proportions are thought to reflect the overall glycolytic and oxidative capabilities of the muscle (Richmond et al. 1999). Particularly, our study shows that Pm muscle and $\mathrm{Rb}$ muscles have a high percentage of $\mathrm{SO}$ fibre types. A positive correlation between the proportions of type I fibres and sensory assessed tenderness in beef (Maltin et al. 1998) and pork (Ockerman et al. 1984) has been found. Similar to other authors (Kiessling and Hansson 1983), our study shows that the Ld muscle is a typical white muscle in which fast-twitch glycolytic fibres dominate. It has been suggested that when there is a high frequency of glycogen depleted fibres at slaughter, especially of type IIB, this will influence meat quality (Karlsson et al. 1999). This is due to the accumulation of lactic acid in the muscle that results in protein denaturation. Extensive protein denaturation can lead to PSE meat (Lopez-Bote et al. 1989).

This study was conducted to investigate the presence of giant fibres in the pig. Giant fibres are characterized by swollen appearance and also show different histochemical staining pattern (Fazarinc et al. 2002). However, apparently giant fibres do not occur in all pig breeds; they were not apparent in Black Sicilian pigs (Velotto et al. 2007). There are different controversies about the occurrence of giant fibres but all authors indicate that these fibres can be detected exclusively in post mortem muscle. In accordance with Rahelic and Puac (1980) we observed giant fibres in the Ld muscle that is a white muscle in which fast-twitch glycolytic fibres prevail in number. The "giant fibre" phenomenon is known to occur in skeletal muscle samples obtained after slaughter and has been described 
in pigs of different breeds (Fiedler et al. 1999; Handel and Stickland 1986) and confirmed in the study of Schubert-Schoppmeyer et al. (2008). Our study shows that there are differences between males and females with regard to the size of all three fibre types; namely, the males showed larger fibres than the females (Figs 5 and 6). In a study carried out on the longissimus muscle from 165 female and 152 intact male Large White pigs of $70 \mathrm{~kg}$, Lefaucheur and Gerrard (2000) found a significantly higher relative area of type I fibres in intact male pigs $(7.6 \pm 2.2 \%)$ than in females $(6.7 \pm 2.5 \%)(P<0.001)$, suggesting that castration effected shortly after birth decreases the relative area of type I fibres in pigs. The muscles of the adult male in most mammalian species tend to be heavier, owing to larger fibre sizes, than those in the adult female. In adult male subjects, type II fibres are usually larger than type I fibres, in contrast to females where type I fibres tend to be larger. In the study of Desanka et al. (2007) no significant difference in the size of both fibre types was found between male and female rats; the fast-twitch type IIA fibres was slightly larger in females. Regarding the fibre size, our study highlights that the crosssectional area of all fibre types was larger in longissimus dorsi than in rhomboideus and psoas minor muscles (Fig. 4). Barone et al. (2000) in their study on the longissimus dorsi muscle noticed a similar result, in fact all three fibre types value areas were twice of that measured in psoas major muscle.

We studied the capillarity, too. The capillary supply, or capillarity, can be expressed as the amount of capillaries per $\mathrm{mm}^{2}$ (capillary density) or per muscle fibre (capillary to fibre ratio). In both cases, the results depend on the cross-sectional areas of the muscle fibres (Dingboom 2002). Our study shows that the psoas minor muscle contains more capillaries per fibre and per $\mathrm{mm}^{2}$ than the rhomboideus and longissimus dorsi. The smaller fibre area of the muscle also resulted in higher capillary density as confirmed by Ruusunen et al. (2004).

Finally, we found some differences between slow and fast fibres both in unloaded shortening velocity and in isometric tension. The values of $\mathrm{P}_{\mathrm{o}}$ and $\mathrm{V}_{\mathrm{o}}$ obtained for the muscle fibres can be compared with published data obtained in other animal species (Pellegrino et al. 2003). We found that isometric tension of FOG fibres was not significantly different from that measured in corresponding fibres of other animal species; both slow fibres and fast twitch glycolytic fibres exhibit lower tension values. Maximum shortening velocity of the fibres considered was higher in FG compared to FOG and SO fibres. Shortening velocity has also been shown to be a major determinant of locomotion energetics, providing an explanation of why small animals use relatively more energy during locomotion than large animals (Rome 1992). Given the important linkages between shortening velocity and muscle function, it is interesting to examine whether any systematic trends exist among the shortening velocities from different skeletal muscles. Hill (1950) predicted that shortening velocity should scale as an allometric function of the body mass, with small animals possessing faster, more powerful muscles. Toniolo et al. (2004) showed the scaling relation between $\mathrm{V}_{\mathrm{o}}$ and body mass and they showed that pig slow fibres conform to the values expected from the scaling equation obtained with other animal species (Pellegrino et al. 2003). The resulting values concerning fast fibres were higher in the pig than those obtained in human fibres and similar to those of rabbit fibres (Pellegrino et al. 2003).

\section{Acknowledgements}

The work was supported by MIPAAF (Italian Ministry of Agricultural, Food and Forestry policies) through PIGVALUE project (D.M. 353/16/0703).

\section{References}

Barone CMA, Abbatiello M, Esposito I, Cappuccio A, Occidente M, Matassino D 2000: Some aspects of meat production in pig autochthonous genetic types. III. Morphometric characteristics of fibre types and adipocytes. Proc. $4^{\text {th }}$ Int. Symp. on Mediterranean pig. Evora (Portugal), 26-28 November 1998. Tradition and Innovation in Mediterranean Pig Production. Options Mediterraneennes, Serie A, n.41, CIHEAM; pp. 233-236 
Davoli R, Fontanesi L, Cagnazzo M, Scotti E, Buttazzoni L, Yerle M, Russo V 2003: Identification of SNPs, mapping and analysis of allele frequencies in two candidate genes for meat production traits: the porcine myosin heavy chain 2B (MYH4) and the skeletal muscle myosin regulatory light chain 2 (HUMMLC2B). Anim Genet 34: 221-225

Depreux FF 2000: Role of MRFs and calcineurin in modulating muscle fiber type. PhD. Thesis, Univ Purdue

Desanka TD, Dimov I 2007: Muscle fiber types and fiber morphometry in the soleus muscle of the rat. Med Bio 3: $121-127$

Dingboom, EG 2002: Equine locomotory muscles: postnatal development and the influence of exercise. PhD. Thesis, Univ Proefschrift, Utrecht, 89 p

Edman KA 1979: The velocity of unloaded shortening and its relation to sarcomere length and isometric force in vertebrate muscle fibres. J Physiol 291:143-159

Fazarinc G, Candek-Potokar M, Ursic M, Vrec M, Pogacnik A 2002: Muscle fibres in pigs with different Ryr1 genotype. Anat Histol Embryol 31: 367-371

Fiedler I, Ender K, Wicke M, Maak S, Von Lengerken G, Meyer W 1999: Structural and functional characteristics of muscle fibres in pigs with different malignant hyperthermia susceptibility (MHS) and different meat quality. Meat Sci 53: 9-15

Fonseca S, Wilson IJ, Horgan GW, Maltin CA 2003: Slow fiber cluster pattern in pig longissimus thoracis muscle: Implications for myogenesis. J Anim Sci 81: 973-983

Gomez De Macedo RM, Dal Pai-Silva M, Dal Pai V, De Assis Fonseca DE, Macedo S, Nunes Martins E 2000: Morphology and histochemistry of muscle fiber types of skeletal muscle tissue of lambs during growth. Acta Scientiarum 22: 581-585

Handel SE, Stickland NC 1986: "Giant" muscle fibres in skeletal muscle of normal pigs. J Comp Pathol 96: 447-457

Henckel P, Ducro B, Oksbjerg N, Hassing L 1998: Objectivity of two methods of differentiating fibre types and repeatability of measurements by application of the TEMA image analysis system. Eur J Histochem 42: 49-62

Hill AV 1950: The dimensions of animals and their muscular dynamics. Sci Prog 38: 209-230.

Karlsson AH, Klont RE, Fernandez X 1999: Skeletal muscle fibres as factors for pork quality. Livestock Prod Sci 60: 255-269

Kiessling KH, Hansson I 1983: Fiber composition and enzymes activities in pig muscle. Swedish J Agric Res 13: 257

Larzul C, Lefaucheur L, Ecolan P, Goguè J, Talmant A, Sellier P, Le Roy P, Monin G 1997: Phenotypic and genetic parameters for Longissimus muscle fibre characteristics in relation to growth, carcass, and meat quality traits in Large White pigs. J Anim Sci 75: 3126-3137

Lefaucheur L, Ecolan P, Barzic YM, Marion J, Le Dividich J 2003: Early postnatal food intake alters myofiber maturation in pig skeletal muscle. J Nutr 133: 140-147

Lefaucheur L, Edom F, Ecolan P, Butler-Browne GS 1995: Pattern of muscle fibre type formation in the pig. Develop Dynam 203: 27-41

Lefaucheur L, Gerrard D 2000: Muscle fibre plasticity in farm mammals. J Anim Sci 77: 1-19

Lopez Bote C, Warris PD, Brown SN 1989: The use of muscle protein solubility to asses pig lean meat quality. Meat Sci 26: 167

Maltin CA, Sinclair KD, Warriss PD, Grant CM, Porter AD, Delday MI 1998: The effects of age at slaughter, genotype and finishing system on the biochemical properties, muscle fibre type characteristics and eating quality of bull beef from suckled calves. Animal Sci 66: 341-348

Ockerman HW, Jaworek D, Vanstavern B, Parrett N, Pearson CJ 1984: Castration and sire effects on carcass traits, meat palatability and muscle fibre characteristics in Angus cattle. Journal of Animal Sci 59: 981-990

Pellegrino MA, Canepari M, D’Antona G, Reggiani C, Bottinelli R 2003: Orthologous myosin isoforms and scaling of shortening velocity with body size in mouse, rat, rabbit and human muscles. J Physiol 546: 677-689

Picard B, Lefaucheur L, Berri C, Duclos MJ 2002: Muscle fibre ontogenesis in farm animal species. Reprod Nutr Dev 42: 415-431

Rahelic S, Puac S 1980: Fiber types in longissimus dorsi from wild and highly selected pig breeds. Meat Sci 50: 431

Richmond FJR, Singh K, Corneil Brian D 1999: Marked non-uniformity of fiber-type composition in the primate suboccipital muscle obliquus capitis inferior. Exp Brain Res 125: 14-18

Rome LC 1992: Scaling of muscle fibres and locomotion. J Exp Biol 168: 243-252

Ruusunen M, Puolanne E 2004: Histochemical properties of fibre types in muscles of wild and domestic pigs and the effect of growth rate on muscle fibre properties. Meat Sci 67: 533-539

Schubert-Schoppmeyer A, Fiedler I, Nurnberg G, Jonas L, Ender K, Maak S, Rehfeldt C 2008: Simulation of giant fibre development in biopsy samples from pig longissimus muscle. Meat Sci 80: 1297-1303

Solomon MB, Dunn MC 1988: Simultaneous histochemical determination of three fibre types in single section of ovine, bovine and porcine skeletal muscle. J Anim Sci 66: 255-264

Toniolo L, Patruno M, Maccatrozzo L, Pellegrino MA, Canepari M, Rossi R, D’Antona G, Bottinelli R, Reggiani C, Mascarello F 2004: Fast fibres in a large animal: fibre types, contractile properties and myosin expression in pig skeletal muscles. J Exp Biol 207: 1875-1886 
Velotto S, Crasto A 2004: Histochemical and morphometrical characterization and distribution of fibre types in four muscles of ostrich (Struthio camelus). Anat Histol Embryol 33: 251-256

Velotto S, Varricchio E, Di Prisco MR, Stasi T, Crasto A 2007: Skeletal myocite types and vascularity in the black Sicilian pig. Acta Vet Brno 76: 163-170

Wojtysiak D, Migdal W 2007: The effect of genotype on muscle fibre characteristics of m. longissimus lumborum of fatteners. Biotech Animal Husbandry 23: 267-275 
Plate I

Velotto S. et al.: New insights ... pp. 169-176

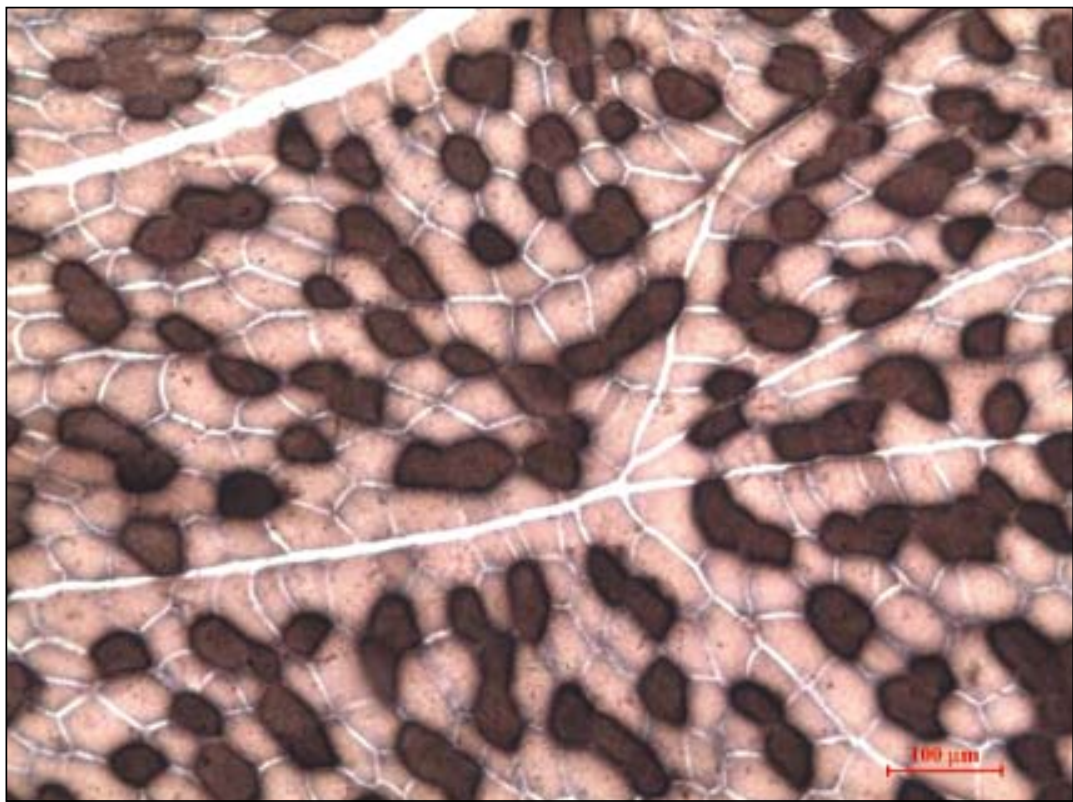

Fig. 1. Psoas minor muscle (male). Identification of fibre types by m-ATPase + SDH combined reaction $(\times 100)$. Fibre types are: I or slow oxidative, SO (darkest area); IIA or fast oxidative glycolytic, FOG (intermediate area) and IIB or fast glycolytic FG (lightest area).

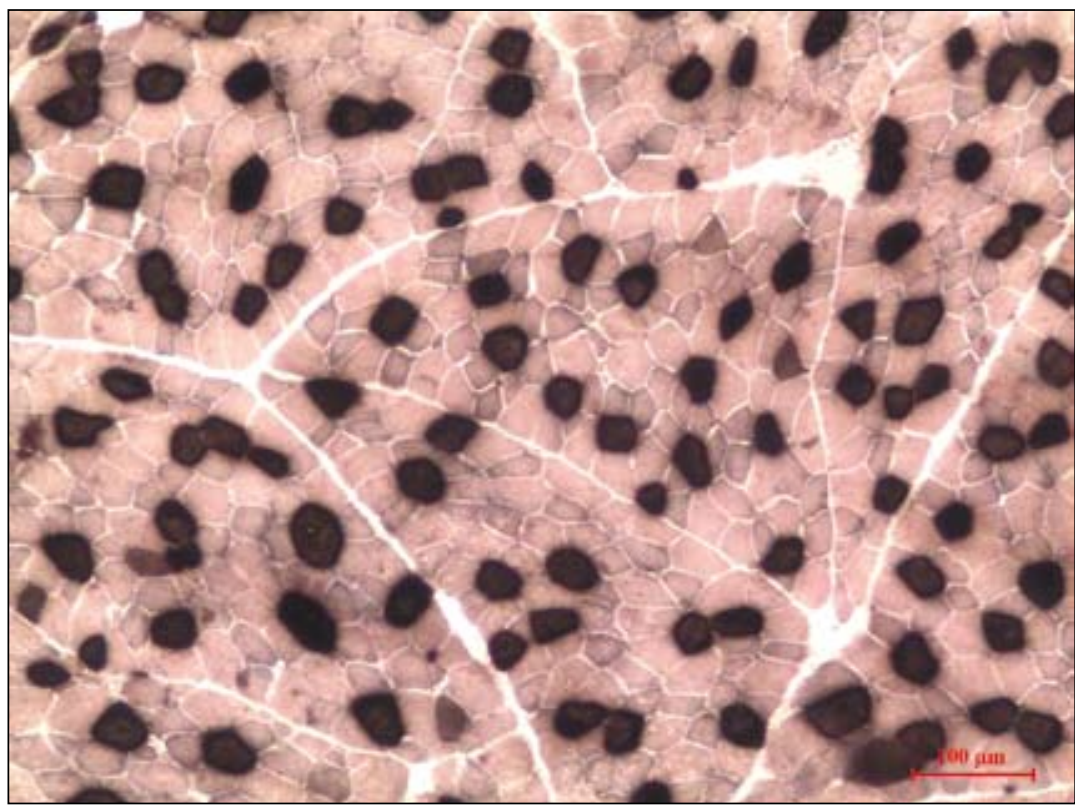

Fig. 2. Longissimus dorsi muscle (male). Identification of fibre types by m-ATPase + SDH combined reaction $(\times 100)$. 


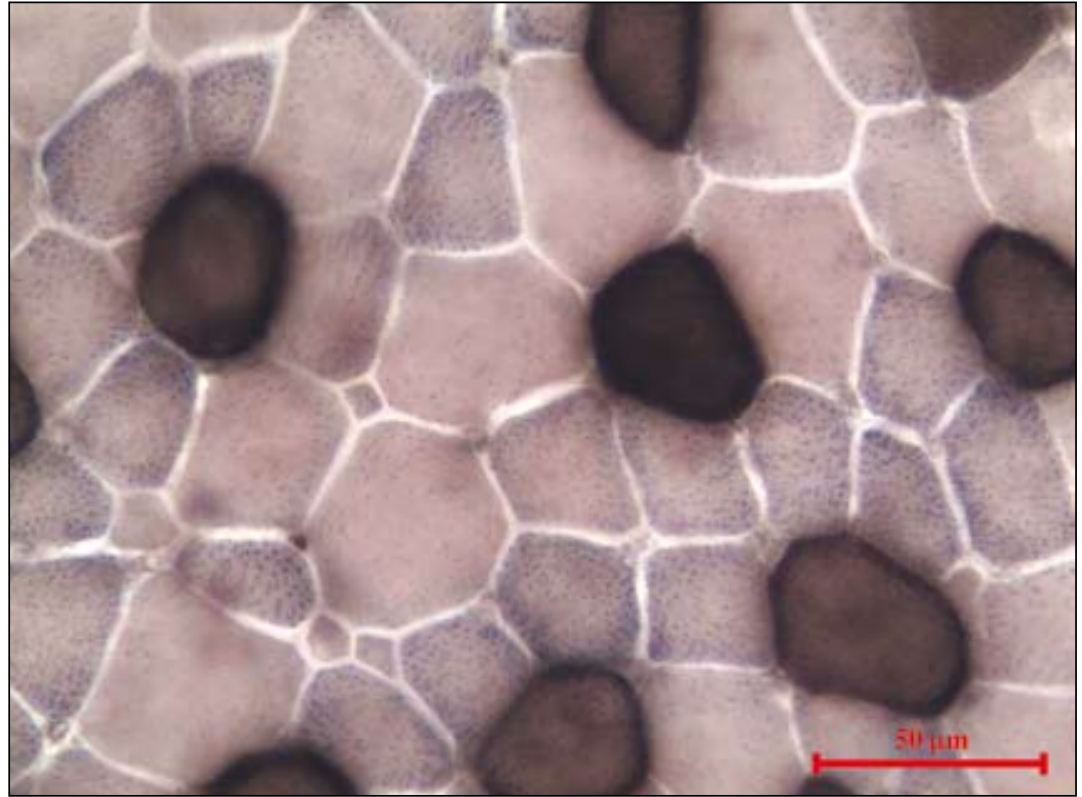

Fig. 3. Psoas minor muscle (female). Identification of fibre types by m-ATPase + SDH combined reaction $(\times 250)$.

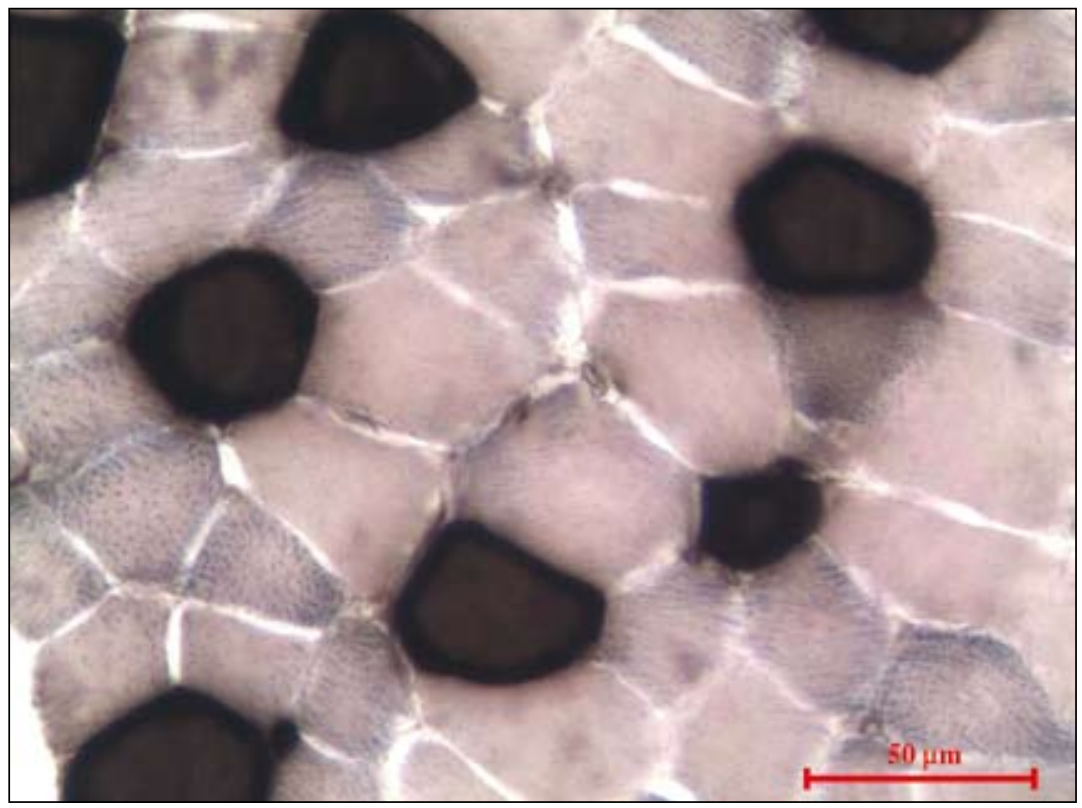

Fig. 4. Longissimus dorsi muscle (female). Identification of fibre types by m-ATPase + SDH combined reaction $(\times 400)$. 


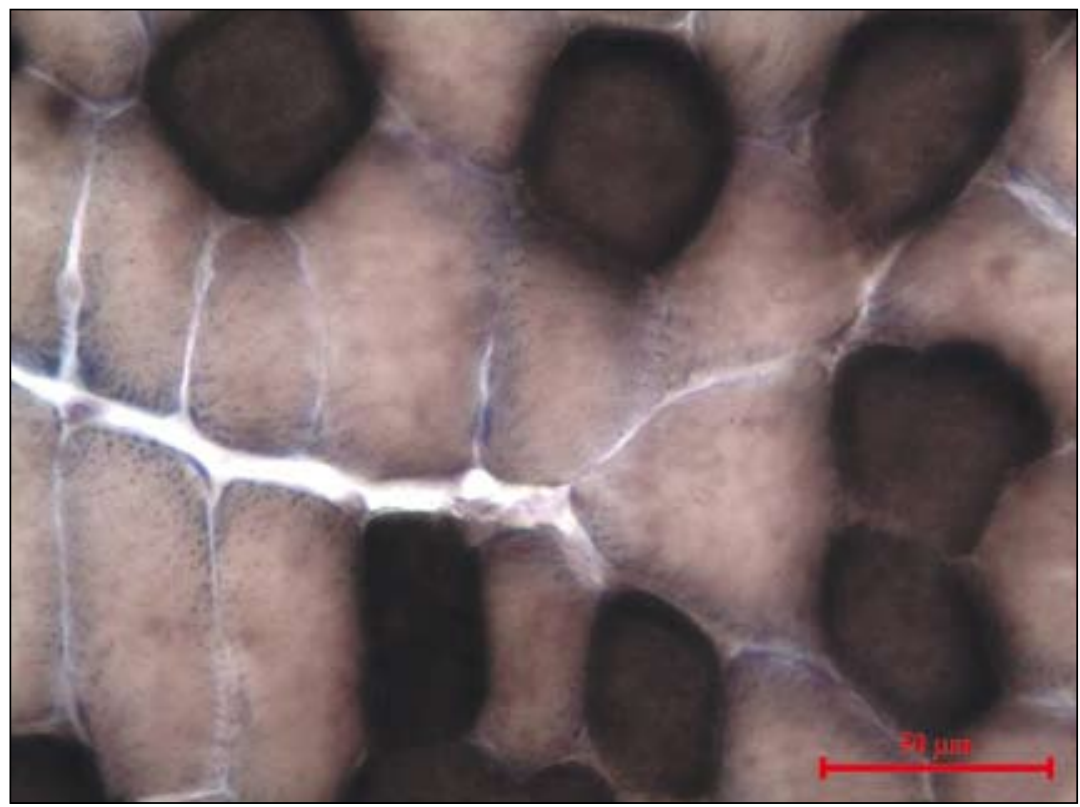

Fig. 5. Rhomboideus muscle (male). Identification of fibre types by m-ATPase + SDH combined reaction $(\times 400)$.

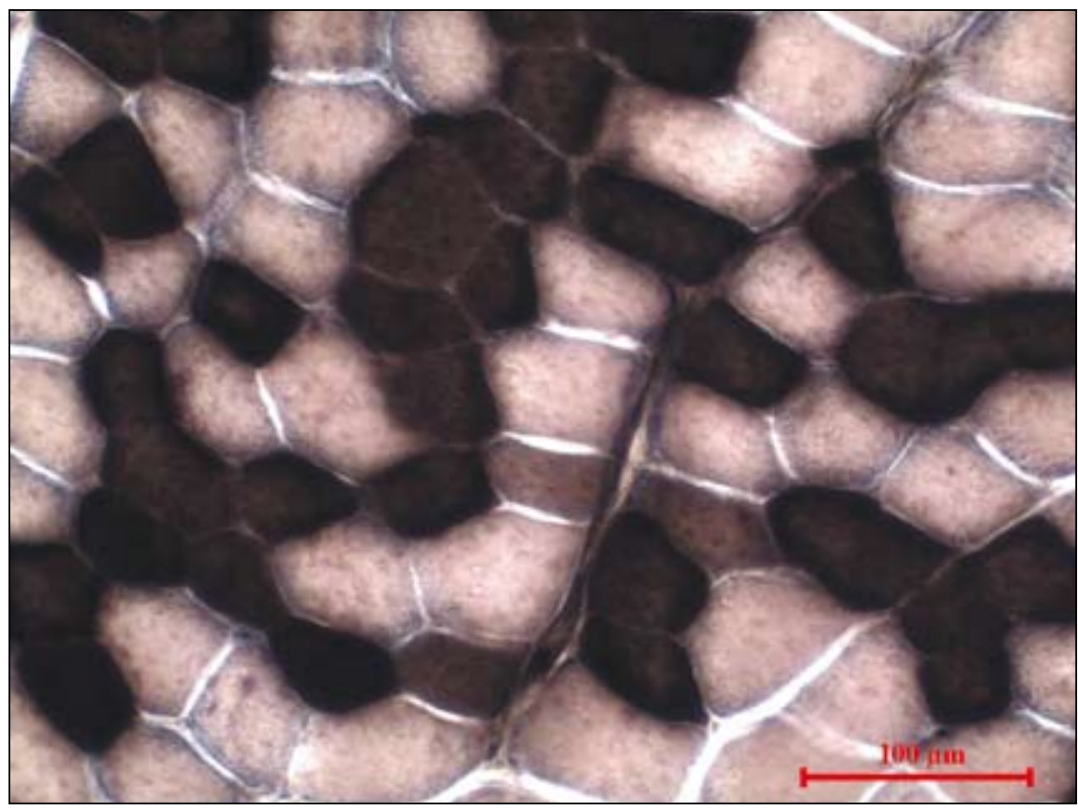

Fig. 6. Rhomboideus muscle (female). Identification of fibre types by m-ATPase + SDH combined reaction $(\times 250)$. 
Plate IV

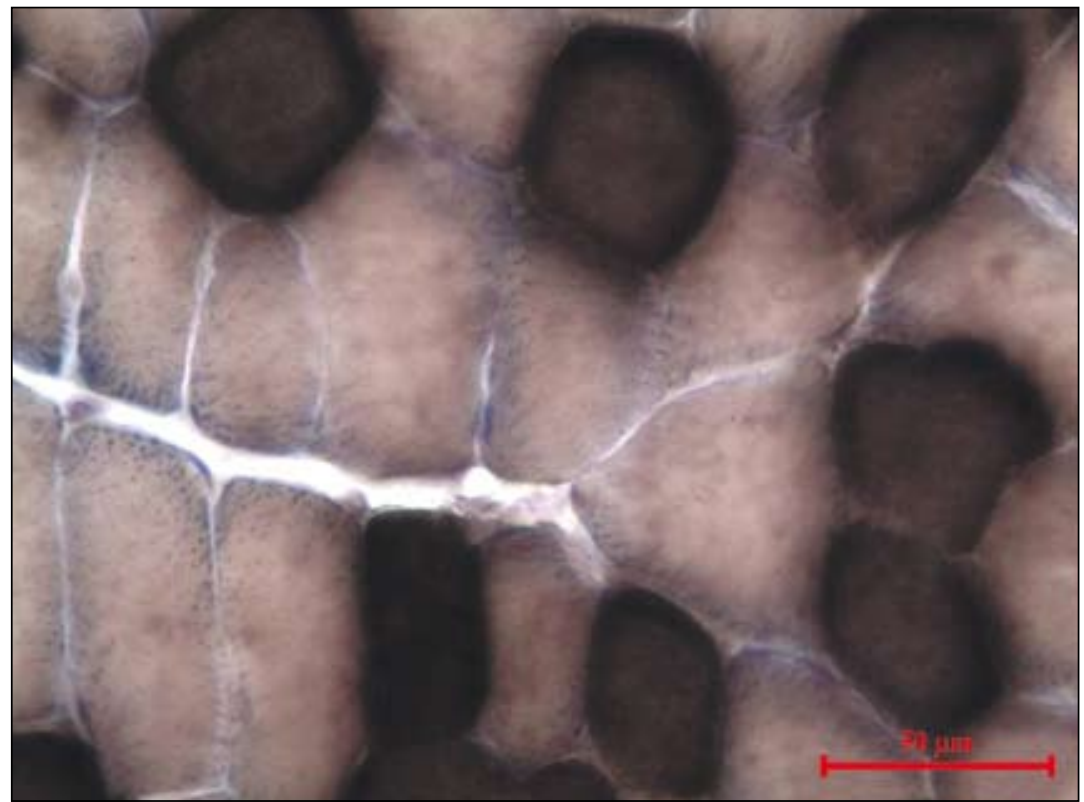

Fig. 7. Longissimus dorsi muscle (female). Identification of fibre types by m-ATPase + SDH combined reaction $(\times 400)$. Distribution of fibres composed of clusters of SO fibres surrounded by FOG and FG fibres. 